\title{
Energy and resource savings in the process of absorption drying of natural gas by glycols
}

\author{
A. A. Ali, M. S. Rogalev \& R. Z. Magaril \\ Department of Oil and Gas Processing, \\ Tyumen State Oil and Gas University, Russia
}

\begin{abstract}
The preparation of natural gas for pipeline transportation using the method of absorption drying by glycols is associated with significant costs of thermal energy required for desorbing water from the saturated solution of glycol, electric energy expenses for pumping the solution between desorber and absorber, a loss of the absorbent within commercial gas due to drop ablation and an increased corrosion rate of equipment due to the chemical aggressiveness of the operating environment. The introduction of surface-active substances into glycol is found to increase the rate of absorption of water from the natural gas and the rate of water evaporation from the saturated solution of the absorbent. Using the nickel salt of synthetic fatty acids in the concentration 20-25 ppm as a surface-active substance leads to a drop down to $10^{\circ} \mathrm{C}$ in the dew point of the dried gas and to an average twofold rise in the evaporation rate of water from the saturated solution of the absorbent. The presence of a given quantity of the nickel salt of synthetic fatty acids in glycol contributes to the suppression of foam formation of the absorbent on the upper plate of the absorber and reduces the corrosion rate of equipment by five times. As a result it becomes possible to decrease the frequency rate of absorbent circulation in the drying system used for obtaining the dried gas with the required properties. This automatically results in a significant decrease in energy consumption. The reductions in permanent losses of the absorbent and the corrosion rate of equipment improve savings on energy resources.
\end{abstract}

Keywords: absorption, desorption, process of mass transfer, surfactants, energy saving, resource saving. 


\section{Introduction}

The process of natural gas absorption dehydration with glycols is discussed in detail in the works [1-7].

The resource and energy saving of the given process is determined by the values of the technical and economic operation indicators of the plant producing the dehydrated gas of the desired quality. The main technical and economic operation indicators of the plant for natural gas absorption dehydration with glycols include absorbent replacement frequency, its irretrievable losses, the frequency of replacement and commissioning of additional equipment during the operation process, electricity expenditure for the absorbent circulation, and thermal energy expenditure for its regeneration. As the gas field operating time increases, the indicators of resource and energy saving of the absorption dehydration process constantly decrease. The reason for this is that the reservoir pressure decrease and the produced natural gas moisture content increase. Moreover, the speed of the produced gas propagation through glycol at the absorber contact stages increases. As a result, the mass transfer of the water vapor from natural gas into the gas phase of glycol degrades. The absorbent entrainment in a drip form with dehydrated natural gas from the absorber increases. In order to obtain natural gas of the required quality the absorbent circulation rate increases and measures are taken in order to reduce the residual water content. The reduction of residual water content in the regenerated absorbent is achieved by increasing the regeneration temperature to values close to the thermal destruction temperature of glycols or transfer of the regeneration units to vacuum distillation. The increase of thermal destruction products in the amount of circulating absorbent leads to a further increase in its drip entrainment in the absorption block and increase of equipment corrosion. Everything listed reduces resource and energy saving of the absorption dehydration process of natural gas with glycols with an increase of the gas field development time.

The analysis of the existing scientific literature on the process of absorption dehydration of natural gas with glycols shows that increase of its energy and resource saving may be achieved by absorbent regeneration improvements.

This paper analyzes the process of saturated absorbent regeneration. The effect of the presence of the surfactant, through the example of a nickel salt of synthetic fatty acids $\mathrm{Ni}(\mathrm{RCOO})_{2}$, towards the given process is considered. On the basis of the described processes there is a proposal formulated to obtain the regenerated absorbent with a residual water content of less than $1 \%$ and the achievement of the minimum content of thermal destruction products within it. Also, the influence of technological parameters on the absorption block operation efficiency is considered. A variant of assessing the performance efficiency of the absorber contact devices is proposed. The degree of impact of the main technological parameters on the mass transfer of the water vapor from the natural gas into the glycol phase on the absorber contact devices is determined. The influence of the presence of surfactants in the regenerated absorbent on the quality of the obtained dehydrated natural gas is described. The 
results of laboratory and industrial testing of the influence of the presence of surfactants on the process of natural gas dehydration with glycols are presented.

\section{Influence of surfactants on the operation of a water-saturated absorbent regeneration block}

We considered the glycols' regeneration process in order to determine an alternative method of its operation, which would provide residual water content in the regenerated absorbent at the level of no more than $1 \%$ with the implementation of the process at a temperature not approaching the thermal destruction temperature of the absorbent.

\subsection{Influence of the presence of surfactant in the saturated absorbent on the water boil-off speed}

It is revealed that the reason for low efficiency of water removal from the saturated absorbent is a lack of speed of its boil-off in the bottom of the stripper. In order to find a solution to this problem we examined the process of water boiloff from the saturated absorbent.

The intensity of the process of water boil-off from the saturated absorbent is determined by the degree of excess of the amount of heat supplied per unit time towards its volume in relation to heat quantity, which is needed to be spent in order to overcome the latent heat of vaporization. The heat balance of the process may be described with the following equation:

$$
Q=G \cdot \lambda+\sigma \cdot S
$$

where $Q$ is the amount of heat supplied to the volume of saturated absorbent per unit time; $G$ is the amount of water boiled off from its volume per unit time; $\lambda$ is the water latent heat of vaporization; $\sigma$ is the surface tension at the interface between the liquid and vapor phases in the volume of the saturated absorbent; $S$ is the total surface of formed vapor bubbles in the volume of the saturated absorbent. From equation (1) it follows that the amount of water boiled off per unit time from it volume may be expressed as follows:

$$
G=\frac{Q-\sigma \cdot S}{\lambda}
$$

This equation shows that the process of water evaporation from the saturated absorbent with constant heat supply to its volume may be accelerated by reducing the surface tension at the interface between the vapor and liquid phases.

In the research [9] a method is proposed for reducing the surface tension at the gas-glycol interface by up to $50 \%$ by means of adding the surfactant $\mathrm{Ni}(\mathrm{RCOO})_{2}$ (where $\left.\mathrm{R}=\mathrm{C}_{9}-\mathrm{C}_{15}\right)$ at a concentration of $25 \mathrm{ppm}$.

We carried out a study on the influence of the presence of the surfactant $\mathrm{Ni}(\mathrm{RCOO})_{2}$ at the concentration of $20-30 \mathrm{ppm}$ in the saturated absorbent, based on the potential glycol content on the speed of water boil-off. The distillation temperature is assumed to be $140^{\circ} \mathrm{C}$ in order to implement the regeneration 
process at a temperature not approaching the thermal destruction temperature. The study results are shown in the Table 1.

Table 1 shows that the lowering of the surface tension at the interface between the vapor and liquid phases results in an acceleration of the process of boiling of glycol water at a constant heat input. This is achieved due to the facilitation of the formation of vapor bubbles in the fluid volume and growth. Used as a surfactant, $\mathrm{Ni}(\mathrm{RCOO})_{2}$ accelerates the boiling of glycol water twofold.

Table 1: Data concerning the influence of the surfactant on the speed of water evaporation from the glycol volume.

\begin{tabular}{|c|c|c|c|c|c|c|c|}
\hline \multirow{2}{*}{ 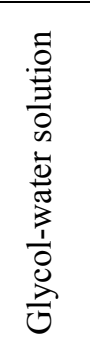 } & \multirow{2}{*}{ 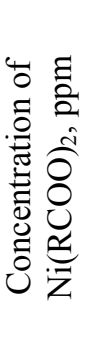 } & \multicolumn{2}{|c|}{$\begin{array}{c}\text { Water concentration } \\
\text { in the glycol-water } \\
\text { solution, } \\
\% \text { of volume }\end{array}$} & \multicolumn{2}{|c|}{$\begin{array}{l}\text { The surface tension at } \\
\text { the glycol-air interface } \\
\text { at } 20^{\circ} \mathrm{C}, \mathrm{mN} / \mathrm{m}\end{array}$} & \multicolumn{2}{|c|}{$\begin{array}{l}\text { The relative } \\
\text { rate of boiling } \\
\text { of water, } \\
\text { units }\end{array}$} \\
\hline & & 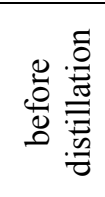 & 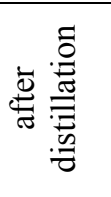 & 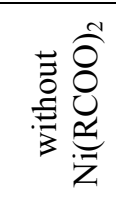 & 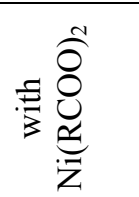 & 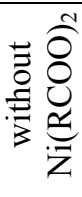 & 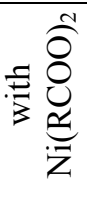 \\
\hline \multirow{3}{*}{$\begin{array}{l}\text { DEG- } \\
\text { water }\end{array}$} & 20 & 5.0 & 1.0 & 48.19 & 29.87 & 1.00 & 1.84 \\
\hline & 25 & 5.0 & 1.0 & 48.19 & 28.67 & 1.00 & 2.01 \\
\hline & 30 & 5.0 & 1.0 & 48.19 & 30.07 & 1.00 & 1.78 \\
\hline \multirow{3}{*}{$\begin{array}{l}\text { TEG- } \\
\text { water }\end{array}$} & 20 & 5.0 & 1.0 & 44.82 & 27.18 & 1.00 & 1.89 \\
\hline & 25 & 5.0 & 1.0 & 44.82 & 26.14 & 1.00 & 2.04 \\
\hline & 30 & 5.0 & 1.0 & 44.82 & 27.34 & 1.00 & 1.82 \\
\hline
\end{tabular}

\subsection{Effect of the presence of surfactant in the glycol on its oxidation and corrosion properties and a tendency to evaporate}

An examination of the existing scientific literature on the process of absorption dehydration of natural gas glycol [1-7] revealed that the resource and energy efficiency of this process has a significant impact on the tendency of the regenerated absorbent towards oxidation, corrosion, and evaporation.

We conducted laboratory studies of the effect of the presence in the absorbent of the surfactant $\mathrm{Ni}(\mathrm{RCOO})_{2}$ at a concentration of $0-50 \mathrm{ppm}$, based on the potential for oxidation of glycol, the corrosive properties of the regenerated glycol and its susceptibility to evaporation. The results of this study are given in Table 2.

These laboratory tests listed in Table 2 indicate that the commissioning glycol nickel salt synthetic fatty acid concentration of $25 \mathrm{ppm}$ reduces the tendency to oxide of glycols by on average $10-15 \%$. The corrosion rate is reduced by about a factor of 8 . The tendency of the glycol to evaporate decreases on average by a factor of 2 . 
Table 2: The results of laboratory studies of the effect of the presence in the absorbent of the surfactant $\mathrm{Ni}(\mathrm{RCOO})_{2}$ on the oxidizing and corrosive properties of the regenerated glycol and its tendency to evaporate.

\begin{tabular}{|c|c|c|c|c|c|}
\hline \multirow{2}{*}{$\begin{array}{c}\text { Concentration } \\
\text { Ni(RCOO) } \\
\text { ppm }\end{array}$} & $\begin{array}{c}\text { Temperature } \\
\text { Glycol in the } \\
\text { experiment, } \\
{ }^{\circ} \mathrm{C}\end{array}$ & \multirow{2}{*}{$\begin{array}{c}\text { Type of } \\
\text { glycol }\end{array}$} & \multicolumn{3}{|c|}{$\begin{array}{c}\text { Changing the operating } \\
\text { characteristics of glycols, \% } \\
\text { relatively }\end{array}$} \\
\cline { 4 - 6 } & 160 & DEG & 100.0 & 100.0 & 100.0 \\
\hline \multirow{2}{*}{0} & 200 & TEG & 100.0 & 100.0 & 100.0 \\
\hline \multirow{2}{*}{10} & 160 & DEG & 94.3 & 93.3 & 73.6 \\
\cline { 2 - 6 } & 200 & TEG & 94.1 & 93.1 & 72.8 \\
\hline \multirow{2}{*}{25} & 160 & DEG & 86.6 & 12.6 & 52.3 \\
\cline { 2 - 6 } & 200 & TEG & 86.7 & 12.7 & 49.8 \\
\hline \multirow{2}{*}{50} & 160 & DEG & 86.5 & 12.5 & 46.8 \\
\cline { 2 - 6 } & 200 & TEG & 86.4 & 12.4 & 46.7 \\
\hline
\end{tabular}

\subsection{The results of testing the influence of the industrial presence of a surfactant in the absorbent on the process of regeneration}

The results of laboratory tests on the influence of input surfactant $\left(\mathrm{Ni}(\mathrm{RCOO})_{2}\right)$ in the amount of glycol in a concentration of $25 \mathrm{ppm}$ in the process of water evaporation from the glycol, its oxidation and corrosion properties as well as the tendency of the absorbent to evaporate were tested under industrial conditions.

The study used a glycol regeneration unit from a complex gas preparation plant north of the Tyumen region. As a diethylene unused absorbent, the glycol regeneration unit operates according to atmospheric distillation, vacuum distillation, and atmospheric distillation with input surfactant $\mathrm{Ni}(\mathrm{RCOO})_{2}$ at a concentration of $25 \mathrm{ppm}$ based on the potential glycol. A trial operation was carried out within 60 calendar days. At the time of trial the complex gas preparation plant by glycol of the Tyumen region is operated within 20 calendar days for each from three schemes of the regenerated absorbent (atmospheric distillation, vacuum distillation, and atmospheric distillation with input surfactant $\left.\mathrm{Ni}(\mathrm{RCOO})_{2}\right)$.

To evaluate the oxidation property of the absorbent, plates of steel 09G2C were mounted in the outlet line from the stripper vapor, the absorbent inlet and outlet of the furnace, and the output from the internal heat exchanger absorber stripper. Evaluation of the propensity of the absorbent to evaporate was estimated by the change of glycol in the reflux tank. Recording of the tendency of the absorbent to oxide was carried out by measuring the light transmission of the glycol before and after the pilot block recovery operation for each circuit operation. The industrial experimental results are shown in Tables 3 and 4.

These experimental operation glycol recovery values shown in Tables 3 and 4 show that the introduction of an absorbent rich in nickel salt of synthetic fatty acid $\mathrm{Ni}(\mathrm{RCOO})_{2}$ at a concentration of $25 \mathrm{ppm}$ based on the potential glycol at a 
Table 3: The pilot operation of the glycol regeneration unit of one of the complex gas preparation plants north of the Tyumen region.

\begin{tabular}{|c|c|c|c|c|c|c|}
\hline \multirow{2}{*}{$\begin{array}{l}\text { The method for } \\
\text { regenerating the } \\
\text { absorbent }\end{array}$} & \multicolumn{2}{|c|}{$\begin{array}{l}\text { Technological } \\
\text { parameters of the } \\
\text { regeneration } \\
\text { process } \\
\end{array}$} & \multicolumn{2}{|c|}{$\begin{array}{c}\text { Content DEG, \% } \\
\text { wt. }\end{array}$} & \multicolumn{2}{|c|}{$\begin{array}{c}\text { Optical } \\
\text { transmission of } \\
\text { the regenerated } \\
\text { absorbent } \% \\
\end{array}$} \\
\hline & 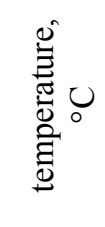 & 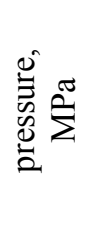 & 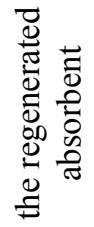 & 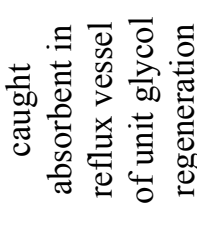 & مّ & 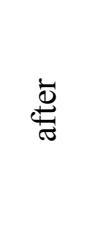 \\
\hline $\begin{array}{l}\text { Atmospheric } \\
\text { distillation }\end{array}$ & 160 & 0.10 & 97.86 & 1.47 & 94 & 90 \\
\hline Vacuum distillation & 160 & 0.07 & 99.21 & 1.92 & 93 & 91 \\
\hline $\begin{array}{l}\text { Atmospheric distilla- } \\
\text { tion by introduction of } \\
\mathrm{Ni}(\mathrm{RCOO})_{2}{ }^{*}\end{array}$ & 160 & 0.10 & 99.73 & 0.73 & 94 & 93 \\
\hline $\begin{array}{l}\text { Atmospheric distilla- } \\
\text { tion by introduction of } \\
\mathrm{Ni}(\mathrm{RCOO})_{2}{ }^{*}\end{array}$ & 145 & 0.10 & 99.49 & 0.61 & 94 & 93 \\
\hline
\end{tabular}

* Input of $\mathrm{Ni}(\mathrm{RCOO})_{2}$ is carried out in the desorbent feed stream by an amount of 25 ppm based on DEG.

Table 4: Data for estimating the rate of corrosion of equipment during the pilot operation glycol regeneration unit of one of the complex gas preparation plants north of the Tyumen region.

\begin{tabular}{|l|c|c|c|c|}
\hline \multirow{2}{*}{$\begin{array}{c}\text { The method for } \\
\text { regenerating the } \\
\text { absorbent }\end{array}$} & $\begin{array}{c}\text { Cutput line of } \\
\text { vapor from } \\
\text { desorbent }\end{array}$ & $\begin{array}{c}\text { input } \\
\text { glycol } \\
\text { in the } \\
\text { oven }\end{array}$ & $\begin{array}{c}\text { output } \\
\text { glycol } \\
\text { from the } \\
\text { oven }\end{array}$ & $\begin{array}{c}\text { the line output from } \\
\text { the built-glycol heat } \\
\text { exchanger desorben }\end{array}$ \\
\hline $\begin{array}{l}\text { Atmospheric } \\
\text { distillation }\end{array}$ & 0.10 & 0.09 & 0.13 & 0.13 \\
\hline Vacuum distillation & 0.09 & 0.08 & 0.11 & 0.11 \\
\hline $\begin{array}{l}\text { Atmospheric } \\
\text { distillation by } \\
\text { introduction of } \\
\text { Ni(RCOO) }\end{array}$ & 0.02 & 0.08 & 0.02 & 0.02 \\
\hline $\begin{array}{l}\text { Atmospheric } \\
\text { distillation by } \\
\text { introduction of } \\
\text { Ni(RCOO) }\end{array}$ & 0.02 & 0.08 & 0.02 & 0.02 \\
\hline
\end{tabular}

* Input of $\mathrm{Ni}(\mathrm{RCOO})_{2}$ is carried out in the desorbent feed stream by an amount of $25 \mathrm{ppm}$ based on DEG. 
constant temperature in the desorber $\left(160^{\circ} \mathrm{C}\right)$ provides relatively classic indicators of absorbent regeneration schemes: deeper regeneration of the absorbent; reduction of deadweight losses due to evaporation; reduction of the oxidative properties of the absorbent; reduction of the corrosion of the process equipment.

Also, the presence in the absorbent of the surfactant reduces the temperature in the stripper to $145^{\circ} \mathrm{C}$ without sacrificing the quality of the resulting absorbent.

\section{Examination of the unit absorption and suggestions to improve the efficiency of its operation}

In this section we assess the impact made by the working values of pressure and temperature on the absorption dehydration. Also, we consider the influence in the dehydration of the presence of the surfactant on its efficiency of operation.

\subsection{Assessing the impact of operating pressures and temperatures on the absorption process of drying}

The study of the absorption process, given in [1,8], shows that the limited step of the absorption process is the diffusion rate of water vapor from the stream of the natural gas into the phase of the absorbent (glycol) through the boundary layer on the contact devise of the absorber.

This process can be described by Fick's first law as follows:

$$
M=\frac{D \cdot S \cdot \tau}{\delta} \cdot\left[\pi \cdot y^{\prime}-P \cdot x^{\prime}\right]
$$

where $M$ is the amount of diffusing water vapor from the gas to the glycol; $D$ is the molecular diffusion coefficient in the diffusion boundary layer; $S$ is the surface of the gas bubbles through bubbling glycol on the plate; $\tau$ is the contact time between the phases; $\delta$ is the thickness of the diffusion boundary layer, the gas-glycol; $\pi$ is the total vapor pressure (absolute pressure in the absorption); $P$ is the vapor pressure of water dissolved in glycol; and $y^{\prime}$ and $x^{\prime}$ are the molar fractions of water in natural gas and glycol respectively.

When considering that the dynamics of interaction between the bubbles of gas with water vapor bubbled through the glycol absorber plates, we propose evaluating the effectiveness of the transfer of water vapor from the natural gas in the glycol phase (efficiency plates) by considering the ratio of diffusing water vapor from the gas in the glycol to the product of the volume of water vapor and its mole fraction in the dried gas $\left(\frac{M}{V_{\text {WATER-GAS }} \cdot y^{\prime}}\right)$, where $V_{\text {WATER-GAS }}$ is the amount of water vapor absorbed from natural gas in a phase of glycol on the plate. 
This ratio can be represented by the following:

$$
\frac{M}{V_{\text {WATER-GAS }} \cdot y^{\prime}}=\frac{D \cdot S \cdot \tau}{V_{\text {WATER-GAS }} \cdot y^{\prime} \cdot \delta} \cdot\left[\pi \cdot y^{\prime}-P \cdot x^{\prime}\right]
$$

When the absorber is working, the volume of liquid on the plate, the interface between the phases and the boundary layer thickness can be considered as constant values. Also, analysis of the expressions (3) and (4) shows that $\pi \cdot y^{\prime}>P \cdot x^{\prime}$. Thus, in expression (3) the component $P \cdot x^{\prime}$ can be neglected.

The coefficient of molecular diffusion of water vapor from the natural gas glycol phase plate and a contact time phases plate can be expressed according to [8], by the temperature and pressure dependencies of the system:

$$
D=k_{1} \cdot \frac{T^{3 / 2}}{\pi}
$$

where $k_{1}$ is the coefficient of proportionality; $T$ is the temperature in the absorber, and

$$
\tau=\frac{V_{\text {GLYCOL }}}{V_{\text {WATER-GAS }}}
$$

where $V_{G L Y C O L}$ is the amount of glycol on the plate absorber.

The volume of water vapor that transferred from the natural gas into the phase of glycol on the contact device of the absorber can be emphasized by the Mendeleev-Clapeyron equation as follows:

$$
V_{\text {WATER-GAS }}=k_{2} \frac{R \cdot T}{\pi}
$$

where $k_{2}$ is the coefficient of proportionality and $R$ is the universal gas constant.

Given the expressions (3) and (5)-(7) proposed for the assessment of the dependence of removal of water vapor from natural gas glycol to the absorber plate, equation (4) can be written in terms of the operating parameters (temperature and pressure) in the following form:

$$
\frac{M}{V_{\text {WATER-GAS }} \cdot y^{\prime}}=K \cdot \frac{\pi^{2}}{T^{1 / 2}}
$$

where $K$ is the coefficient of proportionality $\left[K=\frac{k_{1} \cdot S \cdot V_{G L Y C O L}}{k_{2} \cdot \delta \cdot R^{2}}\right]$.

Based on our proposed relationship (8) for the evaluation of the transition of water vapor in the gas phase glycol (efficiency plates), it can be seen that the produced gas temperature change exerts no significant influence. Maintaining it at a level not exceeding $40^{\circ} \mathrm{C}$ can be achieved by passing the glycol through the available units on the installation of air-cooling before it is fed into the absorber $[1,5]$. Consequently, in the process of absorption drying of natural gas by glycols the value of the pressure in the absorber has a lead role in the diffusion of water vapor from the stream of the natural gas into the phase of the absorbent (glycol) through the boundary layer on the contact devise of the absorber. 
The influence of the surfactant, which can be in the regenerated absorbent on the process of absorption drying of natural gas by glycols The description of the kinetics of mass transfer between the gas and liquid phases in the absorber plates as given in $[1,8]$ does not take into account the influence of surface phenomena on the process.

The passage of vapor through a reflux, located on the plate, requires energy. This is characterized by the amount of heat consumed by evaporation and liberated during the condensation of liquid and the operation for creating an interface between the liquid and gas phases, according to the formula $A=\sigma \cdot S$, where $A$ is the work expended to create the interface between the gas and liquid phases; $S$ is the total surface of the bubbles of the gas phase; and $\sigma$ is the surface tension at the interface between the liquid and gas phases.

For the liquid-gas interface, an interface that is relatively high, the influence of surface phenomena on mass transfer between phases is weak. With an increase in the interface, which occurs due to increased dispersion of the gas phase to the liquid, the influence of surface phenomena becomes relevant. According to research into evaporation/condensation, set out in [10] by FrankKamenetskii, a constant work rate is expended to create an interface between the phases in a liquid-gas interface surface and this is provided by the increase/decrease of the surface tension. Consequently, mass transfer devices for industrial reduction of surface tension at the interface will increase the degree of dispersion of gas in the liquid phase at the contact device. The process described will help to reduce the needed time to reach equilibrium. The result of this will be to increase the efficiency of mass transfer between the gas and liquid phases.

For safety applications, to the change the absorption glycol dehydration of natural gas is not possible over wide ranges of temperature and pressure in the absorber. This explains the feasibility of the practical consideration of the influence of surfactants on the process of absorption of gas dehydration glycols.

We conducted laboratory studies of the effect of the presence in the absorbent of the surfactant $\mathrm{Ni}(\mathrm{RCOO})_{2}$ at a concentration of $0-50 \mathrm{ppm}$, based on the potential of glycol, on the hygroscopic properties of glycols and their tendency to foam. The results of this study are given in Table 5 .

Table 5: The results of laboratory studies on the effect of surfactants on the hygroscopic properties of glycols and their tendency to foam.

\begin{tabular}{|c|c|c|c|c|c|c|}
\hline \multirow{3}{*}{$\begin{array}{l}\text { Concentration } \\
\mathrm{Ni}(\mathrm{RCOO})_{2} \\
\text { in glycol, } \\
\text { ppm }\end{array}$} & \multirow{2}{*}{\multicolumn{2}{|c|}{$\begin{array}{l}\text { Changing the residual } \\
\text { humidity of the gas after } \\
\text { contact with glycol, } \% \text { rel. }\end{array}$}} & \multicolumn{4}{|c|}{$\begin{array}{l}\text { Characteristics of the resulting } \\
\text { foam }\end{array}$} \\
\hline & & & \multicolumn{2}{|c|}{ height, $\mathrm{mm}$} & \multicolumn{2}{|c|}{ lifetime, sec } \\
\hline & DEG & TEG & DEG & TEG & DEG & TEG \\
\hline 0 & $100.0 *$ & $100.0 *$ & 90 & 20 & 12 & 10 \\
\hline 10 & 96.2 & 90.2 & \multirow{3}{*}{\multicolumn{4}{|c|}{ foam not formed }} \\
\hline 25 & 59.4 & 49.7 & & & & \\
\hline 50 & 73.1 & 54.9 & & & & \\
\hline
\end{tabular}

*The relative humidity of the gas remaining after contact with glycol is assumed to be $100 \%$ rel. for DEG $21.2 \%$, for TEG $15.3 \%$. 
The laboratory results in Table 5 show that the commissioning glycol surfactant $\mathrm{Ni}(\mathrm{RCOO})_{2}$ at a concentration of $25 \mathrm{ppm}$ enhances the hygroscopic properties of the absorbent approximately twofold. Glycols in the presence of regenerated $\mathrm{Ni}(\mathrm{RCOO})_{2}$ at $10-50 \mathrm{ppm}$ concentrations provide a complete absence of foaming.

\subsection{The results of industrial testing for the influence of the surfactant within the absorbent, on the operational unit of the absorption drying of natural gas by glycols}

The results of laboratory tests on the influence of input surfactant $\left(\mathrm{Ni}(\mathrm{RCOO})_{2}\right)$ in the amount of glycol in a concentration of $25 \mathrm{ppm}$ in the process of drying gas absorption glycols were tested in an industrial environment.

The study used a block absorption glycol dehydration of natural gas at complex gas preparation plants north of the Tyumen region. In the previous section we presented the results of a pilot operation of the glycol regeneration unit when a surfactant was introduced.

In this section, the results of industrial testing for the influence of the surfactant that is in the absorbent on the operation of the unit of the absorption drying of natural gas by glycols are presented for the three schemes of the regenerated absorbent (atmospheric distillation, vacuum distillation, and atmospheric distillation with input surfactant $\left.\mathrm{Ni}(\mathrm{RCOO})_{2}\right)$. The results of the industrial experiment are shown in Table 6 and Table 7.

Data in Table 6 show that the presence of the regenerated absorbent surfactant $\mathrm{Ni}(\mathrm{RCOO})_{2}$ at a concentration of $25 \mathrm{ppm}$ reduces the dew point of the dried gas on average by a factor of two compared to the traditional scheme of the installation of the absorption gas dehydration glycol. This achieves the absence of deadweight losses from the dried absorbent gas.

Data in Table 7 shows that the presence into the regenerated absorbent of the surfactant $\mathrm{Ni}(\mathrm{RCOO})_{2}$ at a concentration of $25 \mathrm{ppm}$ provides the possibility of reducing by twofold the absorbent circulating in the system.

\section{Conclusions}

The present work shows that the above proposal for a significant increase in resource and energy efficiency in the process of absorption of gas dehydration with glycols can be achieved by improving the quality of absorbent regeneration and reduction of the circulation ratio in the system.

This problem is solved by introducing a surfactant (synthetic nickel salts of fatty acids $\mathrm{Ni}(\mathrm{RCOO})_{2}$ ) at a concentration of $25 \mathrm{ppm}$ in glycol into the saturated absorbent before it is fed into the stripper. This provides the regenerated absorbent with a residual water content of less than $1 \%$. Regeneration of the absorbent can be performed at a temperature of $145^{\circ} \mathrm{C}$. The thermal destruction of glycols doesn't take place in the process of the absorption drying of natural gas by glycols. The presence of $\mathrm{Ni}(\mathrm{RCOO})_{2}$ in the circulating absorbent reduces 
Table 6: The results of the industrial experiments on the influence of the input of $\mathrm{Ni}(\mathrm{RCOO})_{2}$ in the process of drying gas absorption with glycols.

\begin{tabular}{|c|c|c|c|c|c|c|c|}
\hline \multirow[b]{2}{*}{$\begin{array}{l}\text { The method for } \\
\text { regenerating } \\
\text { the absorbent }\end{array}$} & \multicolumn{4}{|c|}{$\begin{array}{c}\text { Technological parameters of } \\
\text { the block absorption } \\
\text { dehydration }\end{array}$} & \multicolumn{3}{|c|}{$\begin{array}{l}\text { Efficiency of operation of gas } \\
\text { glycol dehydration unit }\end{array}$} \\
\hline & 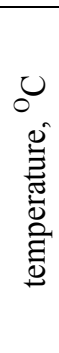 & $\begin{array}{l}\sum^{\pi} \\
0 \\
\vdots \\
\vdots \\
0 \\
0 \\
0 \\
0\end{array}$ & 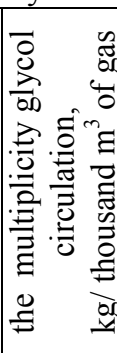 & 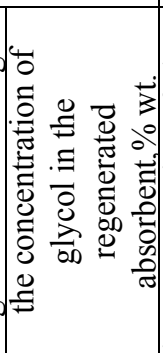 & 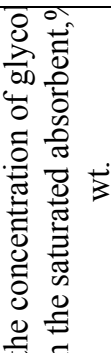 & 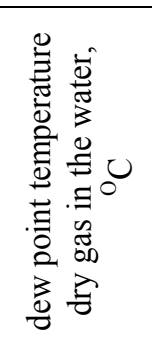 & 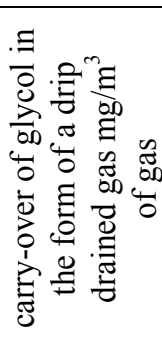 \\
\hline $\begin{array}{l}\text { Atmospheric } \\
\text { distillation }\end{array}$ & 21 & 6.6 & 6.98 & 97.86 & 96.61 & minus 12 & 5.31 \\
\hline $\begin{array}{l}\text { Vacuum } \\
\text { distillation }\end{array}$ & 21 & 6.6 & 6.98 & 99.21 & 96.13 & minus 16 & 3.78 \\
\hline $\begin{array}{l}\text { Atmospheric } \\
\text { distillation } \\
\text { inputting } \\
\mathrm{Ni}(\mathrm{RCOO})_{2} *\end{array}$ & 21 & 6.6 & 6.98 & 99.49 & 95.48 & minus 23 & Traces \\
\hline
\end{tabular}

* Input of surfactant $\left(\mathrm{Ni}(\mathrm{RCOO})_{2}\right)$ is carried out in the desorbent feed stream by an amount of $25 \mathrm{ppm}$ based on DEG.

Table 7: The results of the industrial experiments on the influence of the input of $\mathrm{Ni}(\mathrm{RCOO})_{2}$ in the absorption process of glycol dehydration of natural gas at the circulation rate of the absorbent.

\begin{tabular}{|c|c|c|c|c|c|c|}
\hline \multicolumn{4}{|c|}{$\begin{array}{l}\text { Technological parameters of the } \\
\text { block absorption drying }\end{array}$} & \multicolumn{3}{|c|}{$\begin{array}{c}\text { Efficiency of operation of gas glycol } \\
\text { dehydration unit }\end{array}$} \\
\hline 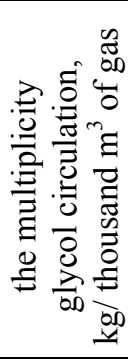 & 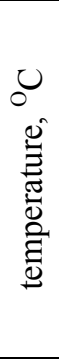 & 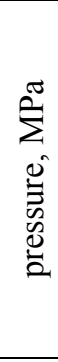 & 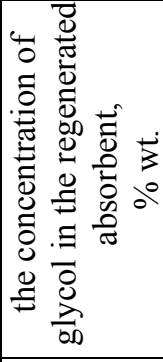 & 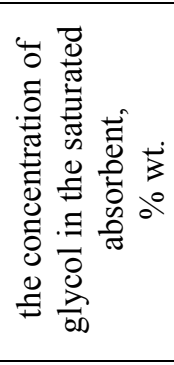 & 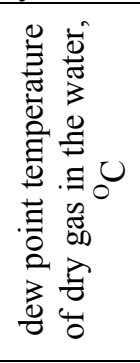 & 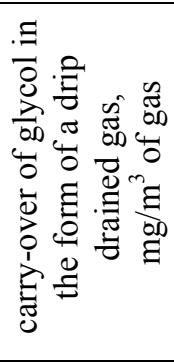 \\
\hline 6,98 & 21 & 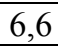 & 99.49 & 95,48 & 1110 & traces \\
\hline 5,58 & 21 & 6,6 & 99.49 & 95,69 & minus 21 & traces \\
\hline 4,89 & 21 & 6,6 & 99.49 & 95,91 & minus 20 & traces \\
\hline 3,49 & 21 & 6,6 & 99.49 & 96,17 & minus 17 & traces \\
\hline
\end{tabular}


the evaporation of glycol in the desorption unit on average by a factor of 2 with a reduction of the corrosion rate by a factor of 5 , the suppression of foaming and complete preservation of the hygroscopic properties of the absorbent. The absence of the foam formation of the absorbent into the absorber reduces the entrainment of glycol to droplet form with the natural gas from the absorber. The technical solution that is shown in this work creates a more profound effect on the $10^{\circ} \mathrm{C}$ temperature of the gas water dew point through the process of the absorption drying of natural gas by glycols. It also enables the possibility of twice-reducing the circulation ratio in the system of absorbent whilst maintaining the existing quality of the natural gas.

\section{References}

[1] Ramm, V.M., The absorption of gases, [in Russian], second edition processing, Chemistry: Moscow, 1976.

[2] Berlin, A.M., Gorechenkov, V.G., Volkov, N.P., Processing of oil and natural gases, [in Russian], Chemistry: Moscow, 1981.

[3] Bekirov, T.M., Lanchakov, G.A., Technology of gas and condensate processing, [in Russian], LLC “Nedra business-center”: Moscow, 1999.

[4] Zhdanova, N.V., Khalif, A.L., Dehydration hydrocarbon gases, [in Russian], Chemistry: Moscow, 1984.

[5] Gritsenko, A.I., Istomin, V.A., Kulkov, A.N., Sulemanov, R.S., Gathering and conditioning of gas on the northern gas fields of Russia, [in Russian], Nedra: Moscow, 1999.

[6] Cole, A.L., Rizenfeld, F.S., Cleaning of gas, [in Russian], Nedra: Moscow, 1986.

[7] Campbell, D.M., Cleaning and processing of natural gases, [in Russian], Nedra: Moscow, 1977.

[8] Kafarov, V.V., Fundamentals of mass transfer, [in Russian], second edition processing, High School: Moscow, 1972.

[9] Ikanin, S.A., Magaril, R.Z., Improve the process of drying of natural gas [in Russian]. Izvestia vyssih ucebyh zavedenij, Neft I gas: Tyumen, 4, pp. 86-90, 2005.

[10] Frank-Kamenetskii, D.A., Diffusion and Heat Transfer in Chemical Kinetics, [in Russian], Nauka: Moscow, 1987. 